\title{
Gender and the smoking behaviour of Ethiopian immigrants in Toronto
}

I Hyman, PhD (1); H Fenta, PhD (2); S Noh, PhD (3)

\begin{abstract}
The objective of this paper is to present descriptive data on gender and smoking among Ethiopian immigrants in Toronto, Canada. The study used a cross-sectional epidemiological survey design $(N=342)$. The main outcome measures identified subjects as current (regular or occasional) smokers, daily smokers and former smokers. Overall, 20.8\% of the individuals in the sample were current smokers and 15.7\% were daily smokers. Although smoking rates (current and daily) were significantly higher among males compared to females, nearly twice as many female as male daily smokers reported that they began smoking post-migration (60.0\% vs. $30.2 \%$ ). Furthermore, $80.0 \%$ of female compared to nearly $56 \%$ of male daily smokers reported that they were smoking more post-migration. A significantly higher proportion of males compared to females were former daily smokers $(17.8 \%$ vs. $4.4 \%)$. These findings present a challenge for public health professionals in terms of preventing the adoption of smoking among Ethiopian females and facilitating smoking cessation among Ethiopian males. Correlates with current smoking suggested that smoking prevention and cessation programs in newcomer immigrant communities may benefit from incorporating social, economic and religious contexts of these newcomers' lives from a gender-specific perspective.
\end{abstract}

Key words: smoking, immigration, gender

\section{Introduction}

Smoking is a major risk factor for mortality and morbidity. ${ }^{1,2}$ Several studies suggest that smoking rates among immigrants to Western countries have increased and this is why many cancer rates among immigrants are converging with those of the nativeborn population. ${ }^{3-5}$ Risk and protective factors associated with smoking behaviour are well documented in the literature. These include age, gender, religiosity, level of education, employment, stress and social support. ${ }^{6-9}$ Among these, gender is a particularly prominent factor for immigrant communities, with female immigrants typically exhibiting significantly lower rates of smoking than males. ${ }^{10-13,16}$ However, few studies have examined smoking and correlates of smoking among recent immigrants to Canada. This information is critical to inform the development of smoking prevention and cessation strategies targeting newcomer communities. This study draws on a community survey of Ethiopian immigrants and refugees in Toronto, Canada. The purpose of this paper is to present descriptive data on the smoking behaviour and on the risk and protective factors associated with smoking in this population.

\section{Literature Review}

Post-migration changes in smoking behaviour are well-documented ${ }^{3-5}$. Less well documented are the determinants of smoking in immigrant populations although proposed models to explain these changes include prolonged exposure to stressful events, adverse circumstances such as disadvantaged socio-economic status or the loss of social networks, smoking behaviour as a coping response to discrimination and poverty, and acculturative changes in beliefs, values and norms about smoking. ${ }^{14,15}$

It is further recognized that immigrants are not a homogeneous group..$^{15}$ Using data from the 1996 National Population Health Survey and the 2000-01 \& 2002-03 Canadian Community Health Surveys, McDonald ${ }^{16}$ found major differences in smoking rates within Canadian immigrants characterized by gender and length of stay in the host country. For example, both immigrant males and females showed an increase in rates of smoking by length of stay in Canada but after adjusting for differences in demographic and socioeconomic characteristics, there was only evidence of significant convergence for male immigrants. Regional differences were also observed. For example, among non-English speaking immigrants born in countries outside of Europe, immigrants from the Middle East and Western Asia were more likely to smoke compared to immigrants from East Asian countries (control group), while immigrants from Southern Asia were less likely to smoke compared to the control group. The logodds ratio for daily smoking for African immigrants was not significantly different from that of the control region of birth.

Gender is increasingly being recognized as a determinant of immigrant women's health. ${ }^{17}$ Gender is known to influence both settlement processes as well as cognitive schemas about health. ${ }^{17,18}$ The intersections of gender with minority

\section{Author References}

1 Department of Public Health Services, University of Toronto

2 The Ontario HIV Treatment Network

3 Department of Psychiatry, University of Toronto

Correspondence: Ilene Hyman, CERIS - The Ontario Metropolis Centre, 246 Bloor St. West, 7th Floor, Toronto, Ontario, Canada, M5S 1V4, Tel: (416) 946-0116, Email: i.hyman@utoronto.ca 
status, income, employment and social integration may impact directly on exposure to stressful events and indirectly on health. ${ }^{18-20}$

Few studies have examined the smoking behaviour or psychosocial and economic determinants of smoking behaviour among specific immigrant populations by gender. It seems clear that to address identified knowledge gaps, smoking research needs to include: 1) studies of the prevalence and correlates of smoking in specific immigrant communities; and 2) intersectional studies that examine smoking behaviour from both a gender and a migration perspective.

\section{Study Background}

Since the mid-1970's, Ethiopia has experienced a major exodus of refugees. An estimated 1.25 million Ethiopians fled to neighbouring countries, such as Sudan, Kenya, Djibouti and Yemen, and a relatively smaller proportion of Ethiopians immigrated to Europe and North America. ${ }^{21}$ Between 1974 and September 1998, over 13000 Ethiopians migrated to Ontario. ${ }^{22}$ According to the Ethiopian Association in Toronto, the current Ethiopian population of Toronto numbers from 45000 to 50 000. In 1997, a partnership was formed between the Culture, Community and Health Studies Program of the Centre for Addiction and Mental Health and the Ethiopian Association in Toronto to examine mental health, health, and access issues experienced by the community. The current paper draws on an epidemiological study, Pathways and Barriers to Health Care for Ethiopians in Toronto, conducted by the authors, that collected extensive data on the health and resettlement experiences of this community. Ethics approval for this research was obtained from the University of Toronto Ethics Board.

\section{Methods}

Sample and Data. The study used a crosssectional epidemiological survey design. A variety of strategies were used to recruit subjects. Using a snowball technique, we identified all possible Ethiopian ethnic, religious, political and social organizations in Toronto and obtained membership lists from each organization. In addition, a list of Ethiopian specific names was compiled using the city telephone directory. Since some Ethiopian Islamic names (e.g. Mohammed, Osman, Fatuma) could not be readily distinguished from nonEthiopian Islamic names, the Islamic names from the telephone directory were compiled separately and given to different Ethiopian Muslim organizations and other Ethiopian associations to identify those who were of Ethiopian origin. We speculated that the Ethiopian organizations and associations in Toronto could know some of these Muslims although they might not necessarily be included in their membership lists. The membership lists from the different organizations, the Ethiopian specific names and non-Ethiopian specific Islamic names from the telephone directory were combined to form a sampling frame.

The resulting sampling frame consisted of 4854 households. From this list, 400 households were selected using simple random sampling method and one individual, eighteen years or older, was selected from each household. Ethiopians who resided in Canada for less than 12 months were excluded from the study. The interviews were conducted by trained Ethiopian interviewers in Amharic. All interviewers underwent extensive training including interview skills training, procedures for contacting potential subjects and general information on immigration, settlement, immigrant health and mental health. The project was announced to the members of the Ethiopian community through religious organizations, community media and a community newsletter. Between May 1999 and May 2000 a total of 342 individuals completed the structured interview with an overall response rate of $85 \%$.

Measurement. Questions on smoking were modelled on those appearing in national and provincial health surveys. All respondents were asked to classify themselves as current smokers (regular or occasional), non-smokers and former daily smokers.
For current smoking status, respondents who were smoking cigarettes at the time of survey, regularly or occasionally, were coded as 1 .

Respondents who smoked cigarettes regularly or occasionally were asked whether they smoked daily. Daily smokers were then asked to provide information on the age they began smoking and the number of cigarettes smoked daily. Using information on age of arrival in Canada and the age at which respondents started smoking daily, we were able to determine the postimmigration onset of smoking - respondents who had started smoking daily in Canada. In a separate question, daily smokers were asked to indicate changes in smoking habits since leaving Ethiopia (smoking more now $=1$, smoking less now $=2$, no change $=3$ ). These two variables were not mutually exclusive.

Former smoking status was determined for respondents who used to smoke daily but now classified themselves as non-smokers or occasional smokers.

An array of potential risk and protective factors were included in the analysis. Marital status was coded as: currently married (1), single, separated, divorced, widowed (0). To determine levels of religiosity respondents were asked to rate the importance of their religious beliefs. Responses were coded as: very important or important (1), not so important or not important (0). Level of education was coded as: high school or less than high school (1), college (2), and university degree (3). Employment was coded as: currently employed (1) and currently not employed (0)

To assess post-migration stress, we used the 14-item recent life events scale included in the Quebec Health Survey (QHS), which was derived from Paykel and colleagues. ${ }^{23}$ The QHS included events specifically relevant to immigrant and minority communities (e.g. trouble because people didn't understand your language, trouble with prejudice or discrimination). Stress was computed as the count of events 
experienced by the respondents during 12 months prior to the interview.

To assess exposure to pre-migration stressors, subjects were asked whether they had experienced pre-migration traumatic exposures to war and killing (coded as yes $=1$, no $=0$ ), or whether they had been interned in a refugee camp (yes $=1$, no $=0)$.

The social support measure used was adapted from Wolchik, et al. ${ }^{24}$ Three dimensions of social support were assessed advice and information, instrumental, and emotional. For each dimension of support, subjective ratings of satisfaction with supports available were obtained on a scale of 1 to 10. In this study, we used the index score that combined the scores of the three dimensions. The scale had internal consistency of 0.96 as measured by Cronbach's alpha.

Data Analysis. Data analysis consisted of descriptive analysis of the study population in terms of socio-demographic characteristics and smoking behaviours. The proportion of the population considered to be former smokers was calculated. Daily smokers were described in terms of the number of cigarettes smoked per day, time of initiation of smoking (i.e. post-migration), and changes in smoking habits since leaving Ethiopia.

Correlates of current smoking were examined using bivariate logistic regression analysis. All analyses were gender-specific. Multivariate analyses for females were not conducted due to small cell sizes for female smokers, a limitation of the present study. Thus the results of this study do not identify a model of smoking; rather, potential risk and protective factors associated with current smoking are identified that can be tested in future studies.

\section{Results}

Sample Description. Table 1 summarizes data on the socio-demographic characteristics of the study sample by gender. Approximately $60 \%$ of the sample was

TABLE 1

Description of the study of population by gender

\begin{tabular}{|c|c|c|c|}
\hline Variable & $\begin{array}{c}\text { Total } \\
(\mathrm{n}=\mathbf{3 4 2})\end{array}$ & $\begin{array}{c}\text { Male } \\
(n=203)\end{array}$ & $\begin{array}{c}\text { Female } \\
(n=139)\end{array}$ \\
\hline Age in years (mean $\pm S D)^{* * *}$ & $35.4 \pm 7.2$ & $36.7 \pm 7.3$ & $33.3 \pm 6.3$ \\
\hline Marital status (married) - (\%) & $55.4 \%$ & $56.5 \%$ & $53.7 \%$ \\
\hline \multicolumn{4}{|l|}{ Religion - (\%) } \\
\hline Ethiopian Orthodox & $67.7 \%$ & $72.1 \%$ & $61.0 \%$ \\
\hline Protestant & $22.3 \%$ & $19.4 \%$ & $22.3 \%$ \\
\hline Roman Catholic & $5.3 \%$ & $3.5 \%$ & $8.1 \%$ \\
\hline Muslim & $2.4 \%$ & $2.0 \%$ & $2.9 \%$ \\
\hline No religion & $2.4 \%$ & $3.0 \%$ & $1.5 \%$ \\
\hline \multicolumn{4}{|l|}{ Importance of religiosity - (\%)* } \\
\hline Religion is important to me & $91.6 \%$ & $88.5 \%$ & $96.2 \%$ \\
\hline Religion is not important to me & $8.4 \%$ & $11.5 \%$ & $3.8 \%$ \\
\hline \multicolumn{4}{|l|}{ Level of education - (\%)*** } \\
\hline High school or less & $32.1 \%$ & $26.0 \%$ & $41.2 \%$ \\
\hline College education & $44.0 \%$ & $41.0 \%$ & $48.5 \%$ \\
\hline University degree & $23.8 \%$ & $33.0 \%$ & $10.3 \%$ \\
\hline Currently employed - $(\%)^{* * *}$ & $78.1 \%$ & $87.6 \%$ & $64.0 \%$ \\
\hline Length of stay in Canada (mean \pm SD) & $9.2 \pm 4.5$ & $9.5 \pm 4.7$ & $8.7 \pm 4.2$ \\
\hline Pre-migration trauma exposure $-(\%)^{* *}$ & $20.8 \%$ & $26.7 \%$ & $11.9 \%$ \\
\hline Refugee camp internment experience - (\%) & $10.6 \%$ & $12.6 \%$ & $7.2 \%$ \\
\hline \multicolumn{4}{|l|}{ Number of post-migration life events - (\%) } \\
\hline no stressful life events & $50.1 \%$ & $48.0 \%$ & $53.3 \%$ \\
\hline 1-2 stressful life events & $36.2 \%$ & $36.6 \%$ & $35.6 \%$ \\
\hline$\geq 3$ stressful life events & $13.6 \%$ & $15.3 \%$ & $11.1 \%$ \\
\hline Satisfaction with social support (mean \pm SD) & $8.3 \pm 1.7$ & $8.2 \pm 1.8$ & $8.5 \pm 1.4$ \\
\hline
\end{tabular}

${ }^{*} p<0.05 ;{ }^{* *} p<0.01 ;{ }^{* * *} p<0.001$

male. The respondents were predominantly a young group with a mean age of 35.3 years, and female respondents were significantly younger than males. The majority of respondents were married (55.4\%) and members of the Ethiopian Orthodox church $(67.7 \%)$. A significantly higher proportion of female respondents considered religion to be very important compared to male respondents $(96.2 \%$ vs. $88.5 \%)$. More than two-third of the respondents $(67.8 \%)$ had some postsecondary education and the majority (78.1\%) were currently employed. Compared to males, females were significantly less likely to have a university education and be employed ( $p<0.001)$. The average length of stay in Canada was 9.2 years (9.5 years for males and 8.7 years for females). A significantly higher proportion of males than females experienced pre-migration trauma $(26.71 \%$ vs. $11.94 \%)$ and refugee camp internment $(12.6 \%$ vs. $7.2 \%)$, although in the latter case the difference was not significant. Approximately half of male and female participants had experienced at least one stressful life event. Males and females were similar in their reported levels of satisfaction with social support.

Descriptive Data on Smoking. Table 2 describes the study population by smoking status and gender. Overall, $20.8 \%$ of the sample were current smokers (used cigarettes regularly or occasionally). The current smoking rate was 2.7 times higher among male respondents $(n=56,27.7 \%)$ compared to female respondents ( $\mathrm{n}=14$, $10.4 \%)$. The gender differential in current 
TABLE 2

Description of the study of population by smoking status and gender

\begin{tabular}{lccc}
\hline Smoking variables & $\begin{array}{c}\text { Total } \\
(\mathbf{n = 3 4 2 )}\end{array}$ & $\begin{array}{c}\text { Male } \\
(\mathbf{n}=\mathbf{2 0 3})\end{array}$ & $\begin{array}{c}\text { Female } \\
(\mathbf{n}=\mathbf{1 3 9})\end{array}$ \\
\hline Current smoker (regular or occasional) $-(\%)^{* * *}$ & 20.8 & 27.7 & 10.4 \\
\hline Former smoker $-(\%)^{* * *}$ & 12.4 & 18.3 & 4.4 \\
Daily smoker $-(\%)^{* * *}$ & 15.7 & 21.3 & 7.4 \\
\hline & $\begin{array}{c}\text { Total } \\
\text { Daily smoking variables }\end{array}$ & $\begin{array}{c}\text { Male } \\
(\mathbf{n}=53)\end{array}$ & $\begin{array}{c}\text { Female } \\
(\mathbf{n}=\mathbf{4 3})\end{array}$ \\
\hline Number of cigarettes smoked daily - Mean (SD) & $12.0(6.7)$ & $12.0(6.7)$ & $11.8(6.7)$ \\
Initiation of daily smoking post-migration $-(\%)^{\text {a }}$ & 35.8 & 30.2 & 60.0 \\
Increase in daily smoking post-migration $-(\%)$ & 60.4 & 55.8 & 80.0 \\
\hline$* * * p<0.001 ;{ }^{2} p<0.1$ & & &
\end{tabular}

${ }^{* * *} p<0.001 ;{ }^{\text {a }} p<0.1$

smoking rates was significant $(p<0.001)$. There was also a significant gender difference in the proportion of the population who were former smokers $(17.8 \%$ males, $4.4 \%$ females, $p<0.001$ )

Among the 53 daily smokers, $21.3 \%$ $(\mathrm{n}=43)$ were male and $7.4 \%(\mathrm{n}=10)$ were female $(p<0.001)$. The mean number of cigarettes smoked daily was similar for males and females (12.0 and 11.8, respectively). Approximately $35.8 \%$ of daily smokers $(\mathrm{n}=53)$ started smoking postmigration and gender differences were apparent; only $30.2 \%$ of males but $60.0 \%$ of females were non-smokers before they left Ethiopia, and began smoking after they left the homeland $(p<0.1)$. Gender differences were also apparent among the respondents to the question on changes in smoking habits since leaving Ethiopia. Approximately $56 \%$ of male smokers and $80.0 \%$ of female smokers reported an increase in smoking post-migration; this difference did not reach statistical significance.

Correlates of Current Smoking. Bivariate associations of current smoking (regular or occasional) with potential risk and protective factors were assessed using logistic regression. Results are shown in Table 3.
Among male respondents, current smokers (compared to non-current smokers), were less likely to report religion as important or very important to them and more likely to have experienced pre-migration trauma, and to have reported higher levels of satisfaction with social support. The same associations were not observed among Ethiopian females. Among Ethiopian females, current smokers (compared to non-current smokers) were less likely to be currently married and more likely to have spent more years in Canada and to have experienced post-migration life events. We found different sets of correlates for males and females. Multiple logistic regression analysis of factors associated with current smoking in men confirmed the results of the bivariate analysis among Ethiopian males. This analysis was not performed for Ethiopian females due to small sample sizes (data available upon request).

\section{Discussion}

Our study findings highlight dramatic gender differentials in the smoking behaviour of Ethiopian males and females, which persist post-migration. Striking differences were also observed in the

TABLE 3

Bivariate logistic regression of factors associated with regular/occasional smoking by gender

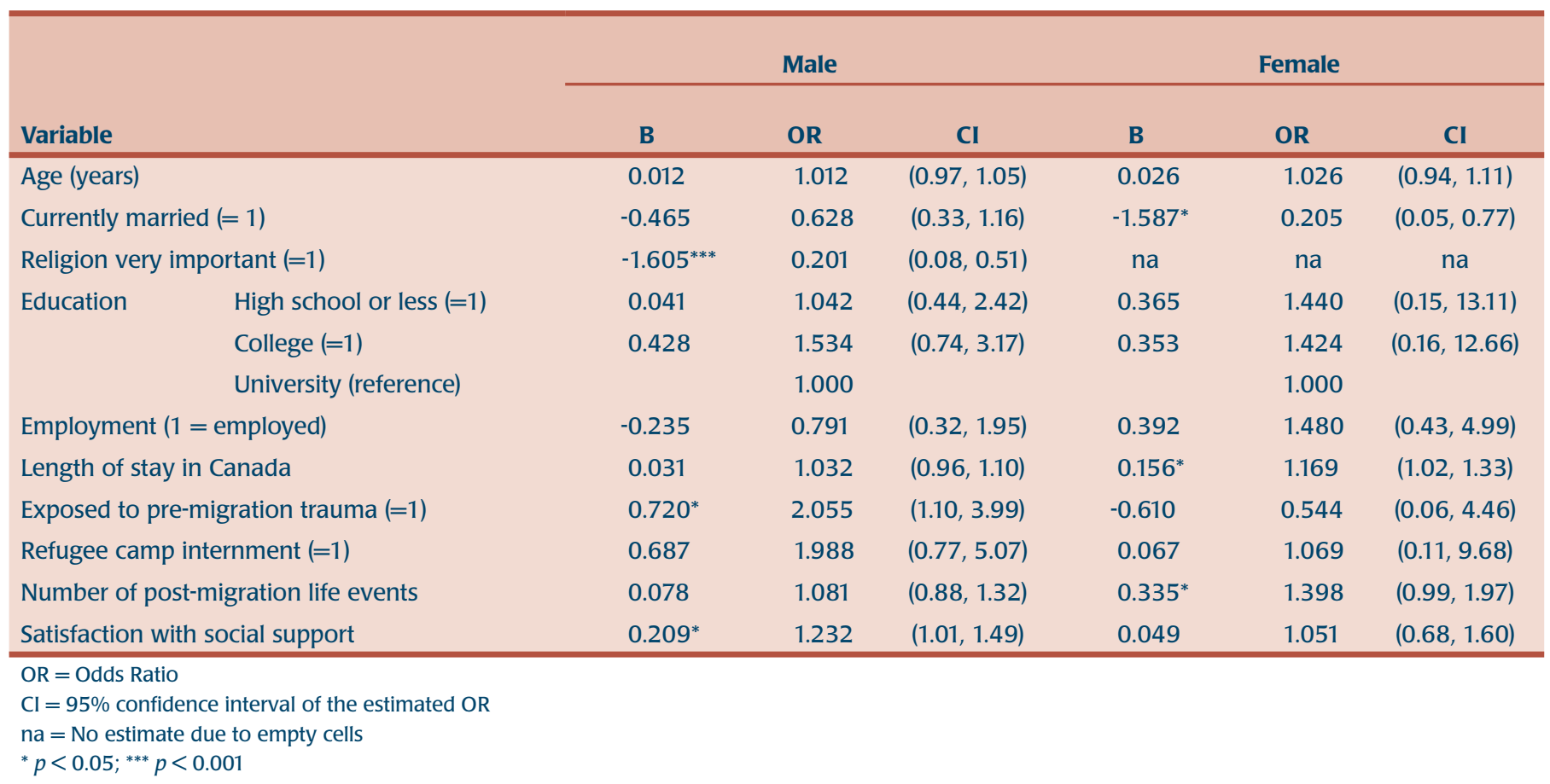


correlates of current smoking by gender. Among Ethiopian males, factors associated with regular or occasional smoking included pre-migration trauma, religiosity, and satisfaction with social support. Female smokers (compared to nonsmokers) were more likely to be married, have spent more years in Canada and to have experienced a higher number of stressful life events.

The results of this study are consistent with gender differentials in smoking rates observed in the 2003 Global Youth Tobacco Survey among Ethiopian students (grades 9-11), which reported smoking rates of $15.2 \%$ and $5.7 \%$ for boys and girls, respectively. ${ }^{25}$ They are also consistent with other studies conducted among native-born and foreign-born populations in the United States that suggest that immigrant women are less likely to smoke than their male immigrant and female native-born counterparts. ${ }^{9-12}$ Although McDonald $^{16}$ did not find significant increases in the log-odds of smoking among immigrant women by length of stay, similar trends were observed for immigrant women. It is also possible that his findings may have masked countryspecific variations in immigrant smoking behaviour.

This study is the first study to collect data on the smoking behaviour of Ethiopian immigrants in Canada. Although current smoking rates in Ethiopia are not available, studies conducted in the 1980 s showed that $38 \%$ of males and $3.4 \%$ of females were smokers, ${ }^{26}$ suggesting that male Ethiopian immigrants may have had a healthier lifestyle (e.g. lower smoking rate) than Ethiopians in their home country, but females appear to exhibit the opposite pattern. Still, compared to smoking rates among males and females in the Toronto population as a whole, the smoking rate for Ethiopian males in Toronto (27.7\%) was slightly higher $(25.6 \%)$, whereas the rate for Ethiopian females in Toronto (10.4\%) was considerably lower $(17.8 \%){ }^{27}$

The data presented in this paper confirm other studies that suggest that immigrant behaviours, such as consumption of a high fat diet, smoking and alcohol abuse, increase over time to resemble those of the majority culture. ${ }^{13,28-29}$ Only $44.2 \%$ of maleand $20.0 \%$ of female- daily smokers reported "no change" in smoking since migration. The vast majority of female daily smokers ( $80 \%$ ) and over half of male daily smokers reported that they were smoking more since they left Ethiopia. Furthermore, $18.3 \%$ of Ethiopian males but only $4.4 \%$ of Ethiopian females could be classified as "former smokers." In the case of male Ethiopians, this is a positive finding, suggesting that the daily smoking rate for Ethiopian males is declining and converging with that of the Toronto male population as a whole. On the other hand, the prevalence of current smoking among females in the Ethiopian community was initially much lower than that among females in the Toronto population as a whole, but may be increasing.

Among Ethiopian males, factors associated with regular or occasional smoking included religiosity and satisfaction with social support. Religiosity had an inverse effect on smoking behaviour (i.e. highly religious people were less likely to smoke). Other studies have found strong religious beliefs and cultural retention to be associated with maintaining healthenhancing behaviour such as a traditional high-fibre diet, non-smoking and non-use of alcohol. ${ }^{15,30-31}$ While social support is usually associated with positive health behaviours, ${ }^{4,32-33}$ in the Ethiopian community, with regards to smoking, the opposite pattern was observed. This may be because many Ethiopian males, particularly without close family in Canada, socialise in smoking environments such as cafes and bars. The same may not be true for women because of social norms restricting women's freedom of movement and gender role expectations. ${ }^{21,34}$

Pre-migration traumatic experiences were associated with an increased risk of smoking, but only among males. This finding was consistent with other research suggesting strong relationships between traumatic stress and smoking behaviour in non-immigrant populations. ${ }^{35-36}$ It is possible that this association was not observed among females because only a small subset of women experienced pre-migration trauma and smoked.

Despite the finding that Ethiopian males experienced more stressful life events compared to Ethiopian females, postmigration stressful life events were only associated with regular or occasional smoking in the latter group. The acculturative stress model proposes that immigrants turn to artificial support when they find the experience of immigration stressful and disorienting. Alternatively, it has been suggested that alcohol and substance use are "learned" as a part of an assimilation process. ${ }^{37}$ Our findings suggest that male and female Ethiopian immigrants may use different coping behaviours in response to stress. For example, Ethiopian women may have less opportunity to consume alcohol and drugs and/or these behaviours may be considered less culturally acceptable compared with smoking.

Our finding that females who resided in Canada longer were more likely to smoke is not surprising. A study of pregnant Southeast Asian immigrant females in Montreal found that women who were in Canada longer were less likely to report adequate social support and more likely to report stressful life experiences than newcomer immigrant women. ${ }^{38}$ Similarly newcomers' strategies for coping with stress may also change with time spent in the host country.

The present study was the first community health survey of Ethiopian immigrants in North America. Among its strengths are the attempts made to develop a comprehensive sampling frame and the excellent response rate. However the study had certain limitations that must be acknowledged. Firstly, potential candidates were excluded if they had no telephone, stable address or membership status in Ethiopian organisations. Secondly, the low prevalence rate of smoking among Ethiopian females in the study population limited statistical power and prevented the identification of interaction terms in a multivariate logistic regression analysis.

These findings present an obvious challenge for public health professionals and 
the Ethiopian community; that is, how to prevent the adoption of smoking among Ethiopian females and how to facilitate smoking cessation among Ethiopian males. Feminist researchers increasingly view smoking and substance abuse not simply as a negative lifestyle choice but as a rational response to real pressures associated with gender and class inequity..$^{39-40}$ New immigrant women face multiple and more barriers to maintaining or changing health behaviour, compared to women in the general population. ${ }^{42-43}$ Study findings suggest that smoking prevention and cessation programs in the Ethiopian community must acknowledge and address the gender, social and religious contexts of these newcomers' lives. These findings are equally relevant to other newcomer communities in Canada who may experience similar contextual and genderspecific issues.

\section{Acknowledgements:}

Support from our community partner, the Ethiopian Association in Toronto. Funding from the Centre of Excellence for Immigration and Settlement (CERIS) and Heritage Canada. The authors acknowledge the contribution of Dr. Lorraine Greaves, Executive Director, British Columbia Centre of Excellence for Women's Health who reviewed the final manuscript.

\section{References}

1. Heart and Stroke Foundation of Canada. The Changing Face of Heart Disease and Stroke in Canada 2000. Ottawa: Heart and Stroke Foundation of Canada, 1999.

2. Cancer Care Ontario. Cancer Incidence and Mortality in Ontario, 1964-1996. Toronto: Cancer Care Ontario, 2000.

3. Kliewer EV, Smith KR. Ovarian cancer mortality among immigrants in Australia and Canada. Cancer Epidemiol Biomarkers Prev. 1995;4:453-58.
4. Acevedo M. The role of acculturation in explaining ethnic differences in the prenatal health-risk behaviours, mental health, and parenting beliefs of Mexican American and European American at-risk women. Child Abuse Neglect. 2000;24:111-27.

5. Acevedo-Garcia D, Pan J, Jun HJ, Osypuk TL, Emmons KM. The effect of immigrant generation on smoking. Soc Sci Med. 2005;61:1223-42.

6. Ng E, Wilkins R, Gendron F, Berthelot JM. Dynamics of Immigrants' Health in Canada: Evidence from the National Population Health Survey. 2005. URL: http://www. statcan.ca:8096/bsolc/english/bsolc?catno = 82-618-MWE2005002

7. Public Health Agency of Canada. Toward a Healthy Future: Second Report on the Health of Canadians. 1999. URL: http:// www.phac-aspc.gc.ca/ph-sp/phdd/report/ toward/index.html

8. Baron-Epel O, Haviv-Messika A, Tamir D, Nitzan-Kaluski D, Green M. Multiethnic differences in smoking in Israel: Pooled analysis from three national surveys. Eur J Public Health. 2004;14:384-89.

9. Maxwell AE, Bernaards CA, McCarthy WJ. Smoking prevalence and correlates among Chinese- and Filipino-American adults: Findings from the 2001 California Health Interview Survey. Prev Med. 2005;41:693-99.

10. Wilkinson LM, Spitz MR, Strom SS, et al. Effects of nativity, age at migration, and acculturation on smoking among adult Houston residents of Mexican descent. Am J Public Health. 2005;95:1043-49.

11. Taylor KL, Kerner JF, Gold KF, Mandelblatt JS. Ever vs. never smoking among an urban, multiethnic sample of Haitian-, Caribbean-, and US-born blacks. Prev Med. 1997;26:855-65.
12. King G, Polednak AP, Bendel R, Hovey D. Cigarette smoking among native and foreign-born African Americans. Ann Epidemiol. 1999;9:236-44.

13. Chen J, Ng E, Wilkins R. The health of Canada's immigrants in 1994-5. Health Rep. 1996;7(4):33-45.

14. Albrido-Lanza AF, Armbrister AN, Florez KR, Aguirre AN. Toward a theory-driven model of acculturation in public health research. Am J Public Health. 2006;96:1342 1346.

15. Hyman I. Immigration and Health. Working Paper 01-05. Health Policy Working Paper Series. Ottawa: Health Canada, September, 2001. URL: http://www.hc-sc.gc.ca/iacbdgiac/arad-draa/english/rmdd/wpapers/ wpapers1.html

16. McDonald JT. The health behaviours of immigrants and native-born people in Canada. Working Paper No 01-06. Halifax/ Moncton: Atlantic Metropolis Centre, 2006.

17. Thurston WE and Vissandjee B. An ecological model for understanding culture as a determinant of women's health. Critical Public Health. 2005;15:229-242.

18. Walters V. The social context of women's health. BMC Women's Health. 2004; 4: S2.

19. Im E \& Yang K. Theories on immigrant women's health. Health Care for Women International. 2006;6:666-681.

20. Agnew V. Gender, Migration and Citizenship Resources Project, Part II: A Literature Review and Bibliography on Health. Toronto: Centre for Feminist Research, York University, 2002.

21. McSpadden L, Moussa H. I have a name: The gender dynamics in asylum and in resettlement of Ethiopian and Eritrean refugees in North America. J Refugee Studies. 1993;6:203-25. 
22. George U, Mwarigha MA. Consultation on Settlement Programming for African Newcomers: Final report. Toronto: University of Toronto: Centre for Applied Social Research, 1999.

23. Paykel ES, Mayers JK, Diendelt MN, Klerman GL, Lindenthal JJ, Pepper MP. Life events and depression: A controlled study. Arch Gen Psychiat. 1969;25:340-47.

24. Wolchik SA, Beals J, Sandler IN. Mapping children's support networks: Conceptual and methodological issues. In: Belle D, ed. Children's Social Networks and Social Supports. New York: John Wiley \& Sons, 1989:191-220.

25. Centres for Disease Control. 2003. Ethiopia - Addis Ababa Global Youth Tobacco Survey (GYTS). URL: http://www.afro. who.int/tfi/publications/gyp_factsheet/ ethiopia/addis_ababa.2003.doc

26. World Health Organization. Tobacco or Health: A Global Status Report, Country Profiles by Region. 1997. URL: http:// www.cdc.gov/tobacco/who/whofirst.htm.

27. Toronto Health Profiles. 2001. URL: http:// www.torontohealthprofiles.ca/

28. Hyman I. Immigrant and visible minority women. In: Stewart DE, Cheung A, Ferris LE, Hyman I, Cohen M, Williams IJ, eds. Ontario Women's Health Status Report. Toronto: Ontario Women's Health Council, 2002:338-58
29. Statistics Canada. How Healthy are Canadians? Annual report. Ottawa: Statistics Canada, 1999. Cat. No. 82-003SIE.

30. Marmot MG, Syme SL. Acculturation and coronary heart disease in JapaneseAmericans. Am J Epidemiol. 1976; 104:225-47.

31. Scribner R, Dwyer JH. Acculturation and low birthweight among Latinos in the Hispanic HANES. Am J Public Health. 1989;79:1263-67.

32. Sabogal F, Marin G, Otero-Sabogal R, Marin BV, Pérez-Stable EJ. Hispanic familism and acculturation: What changes and what doesn't? Hispanic J Behav Sci. 1987;9:397-412.

33. Suarez L. Pap smear and mammogram screening in Mexican-American women: The effects of acculturation. Am J Public Health. 1994;84:742-46.

34. Matsuoka A, Sorenson J. Ghosts and Shadows: Construction of Identity and Community in an African Diaspora. Toronto: University of Toronto Press, 2001:13-14.

35. Vlahov D, Galea S, Ahern J, et al. Consumption of cigarettes, alcohol, and marijuana among New York City residents six months after the September 11 terrorist attacks. Am J Drug Alcohol Ab. 2004;30:385-407.

36. op den Velde W, Aarts PGH, Falger PRJ, et al. Alcohol use, cigarette consumption and chronic post-traumatic stress disorder. Alcohol Alcoholism. 2002;37:355-61.
37. Rebhun LA. Substance use among immigrants to the United States. In: Loue S, ed. Handbook of Immigrant Health. New York: Plenum Press, 1998:493-519.

38. Hyman I, Dussault G. Negative consequences of acculturation: Low birthweight in a population of pregnant immigrant women. Can J Public Health. 2000;91:357-61.

39. Adrian M, Lundy C, Eliany M, eds. Women's use of alcohol, tobacco and other drugs in Canada. Toronto: Addiction Research Foundation, 1996.

40. Horne T. Women and Tobacco. A Framework for Action. Ottawa: Health Canada, 1995.

41. Gomberg ESL and Nirenberg TD. Antecedents and Consequences. In Gomberg ESL and Nirenberg TD eds. Women and Substance Abuse. New Jersey: Ablex Publishing Corporation, 1993.

42. Oxman-Martinez J, Abdool SN and Loiselle-Leonard M. Immigration, women and health in Canada. Can J Public Health. 2000; 91:394-395

43. Vissandjee B, Weinfeld M, Dupéré S, et al. Sex, gender, ethnicity and access to health care services: Research and policy challenges for immigrant women in Canada. JIMI. 2001;2(1) 